\title{
Don Quixote and Sancho Panza as Archetypes of the Legal Consciousness in Spain. New Methodology of History of Law
}

\author{
Elena Yu. Kalínina* \\ Herzen State Pedagogical University of Russia \\ 48 Moyka River Embankment, St. Petersburg, 191186, Russia
}

Received 05.12.2018, received in revised form 28.12.2018, accepted 09.01.2019

Two points of this research are of great value for the jurisprudence. On the one hand, the study proposes a new research methodology, based on the interdisciplinary scientific approach. On the other hand, results of the application of the new methodology are considered on the example of the analysis of the novel "Don Quixote".

The science of the history of state and law proposes to use the methods inherent in other humanities, whose object of study includes the same phenomena. For example, the state is more or less studied within different sciences; therefore, a more complete image will surely be formed, if we put together different elements of a mosaic.

This approach supposes the application of unconventional sources, which were not used in the jurisprudence being informally prohibited and considering irrelevant. As a source of this type the text of fiction is used there. The study shows that the text of a novel is capable of reconstructing a number of historical and legal events. By the other hand-and it is more important - it is possible to reconstruct peculiarities of legal consciousness of the epoch by means of the text of the literature of fiction.

Keywords: legal consciousness, interdisciplinary methodology, archetypes, history of law, Cervantes, Don Quixote, Spain of the $17^{\text {th }}$ century.

Research area: philology.

Citation: Kalínina, E.Yu. (2019). Don Quixote and Sancho Panza as archetypes of the legal consciousness in Spain. New methodology of history of law. J. Sib. Fed. Univ. Humanit. soc. sci., 12(1), 77-88. DOI: 10.17516/1997-1370-0381.

(C) Siberian Federal University. All rights reserved

* Corresponding author E-mail address: bellaflor@mail.ru ORCID 0000-0002-9489-6762

This work is licensed under a Creative Commons Attribution-NonCommercial 4.0 International License (CC BY-NC 4.0). 


\title{
Don Quijote Y Sancho Panza Como Arquetipos \\ De La Conciencia Jurídica Española. Nueva Metodología Para EI Historiador Del Derecho
}

\author{
Elena Yu. Kalínina \\ Universidad Estatal Pedagógica de Rusia A. Herzen \\ San Petersburgo, Rusia
}

\begin{abstract}
$\overline{\text { En el presente estudio dos aspectos son de interés para un investigador, sobre todo para un }}$ historiador del Derecho y de las Instituciones Politicas. Por un lado, es una metodología nueva de investigación, basada en un enfoque interdisciplinar. Por otro lado, se exponen los resultados de la aplicación de esta metodología. Como ejemplo se propone la novela de Miguel de Cervantes, Don Quijote.

En el marco de la ciencia de la historia del Derecho y de las Instituciones Politicas se pueden aplicar métodos propios de otras ciencias humanitarias, que como objeto estudian fenómenos estatales. El Estado mismo es el objeto de casi todas las humanidades, por esto una imagen más clara de la realidad política y legal puede formarse cuando se componga un mosaico de piezas diferentes que encajen.

Esta metodología supone la aplicación de fuentes no tradicionales, que en la ciencia jurídica antes parecían casi imposibles por una prohibición tácita. Un ejemplo de fuentes de este tipo es el texto artístico. En esta investigación se demuestra que por medio del texto artístico o de la novela de ficción es posible reconstruir acontecimientos históricos importantes para el estudio de la historia del Derecho. Por otro lado, y es lo más importante, por medio del texto literario se pueden revelar las particularidades de la conciencia jurídica de la época.
\end{abstract}

Palabras clave: Conciencia jurídica, metodología interdisciplinar, arquetipos, historia del Derecho, Cervantes, Don Quijote, España del siglo XVII.

\section{Introducción. La reconstrucción de la realidad a través del texto literario}

El texto artístico es una forma especial de la asimilación y de la reconstitución del mundo que nos rodea, es un modelo de la realidad, no de la existencia sino de la conciencia, el modelo en cierta manera interpretador, transformador de la realidad En este sentido, el texto artístico es una cuasi realidad (Sabitova, Ekshembeeva, 2012). Por esto si hablamos de la clásica obra de arte del carácter global, que es, sin duda, Don Quijote de La Mancha, podemos reconstruir una serie de características intrínsecas de la época y de la conciencia social a través de la conciencia del autor.

Cualquier investigador que se ocupe de la reconstrucción histórica, que aspire a ver el mundo con los ojos de la gente que vivió en el período histórico estudiado, es capaz de aprender más acerca de la realidad de la época que se encuentra en el ámbito de su 
interés. Parece que la investigación más curiosa fue la que llevó a cabo el investigador actual,Vladímir Ponomariov, que describió desde el punto de vista de un médico el comportamiento de Don Quijote como desviado, de la misma forma que diagnosticó el estado de la salud psíquica de uno de los personajes secundarios con quien se encontró en su andanzas el Caballero de la Triste Figura (Ponomarev, 2016).

Investigaciones de este tipo abren perspectivas extraordinarias en esferas diferentes de las ciencias humanas y sociales, así como en la psicología. La realización de estos estudios podría aproximarnos a una profunda comprensión de la realidad histórica, y permitirnos echar una mirada al mundo del pasado en el contexto del observador de la época.

Un problema similar se planteó como objetivo el historiador moderno, especialista en el Medievalismo español, Oleg Aurov. Planteó si la imagen del mundo del protagonista era un reflejo, aunque fuera distorsionado, de la realidad, o era uno de los mundos que habían surgido en la mente del autor (Aurov, 2014: 116). Este científico explora la realidad histórica, relacionada ante todo con el desarrollo de la caballería, es decir, la realidad del siglo XIII, de la que tenemos una gran cantidad de obras literarias, históricas, jurídicas, etc. Llama la atención que en los textos de la época se formaran los fundamentos de la literatura de ficción posterior. En el presente artículo, por el contrario, se afirma que en la ficción se refleja vivamente la realidad política, jurídica y económica. En la novela se puede obtener referencias sobre ciertos eventos importantes. Es bien conocido que el gran escritor ruso Fiódor Dostoyevski estudió cuidadosamente la crónica criminal de la prensa para escribir novelas, y al conocerlo podemos hacer una reconstrucción inversa de los acontecimientos reales. También se pueden estudiar los conceptos ideológicos del Estado, transmitidos, en particular, a través de los textos jurídicos.

\section{Un ejemplo de la aplicación de la nueva metodología basada en el enfoque interdisciplinar}

Oleg Aurov presentó un plan bastante detallado para el posible estudio de la influencia en la formación de la imagen de Don Quijote de los textos jurídicos de la época, ante todo de los textos de Alfonso X el Sabio en particular, de las Siete Partidas. La Segunda Partida está dedicada a la descripción del estatuto social y legal del caballero (Aurov, 2014: 121). Este artículo de O. Aurov demuestra un profundo conocimiento del marco jurídico de la Edad Media por parte de Cervantes. Esta afirmación es importante para lo que se va a decir más abajo. 
La crítica principal a la aplicación de este método (el interdisciplinar) puede consistir en que las imágenes artísticas pueden convertirse en arquetipos, si representan pautas de la conducta y de la concepción del mundo más significativos no solo de su época, sino de los tiempos remotos. Este puede ser un problema para un investigador. El arquetipo es un fenómeno atemporal. Es un elemento invariable o un componente de la cultura poco variable en el tiempo y en el espacio. Sin embargo, a pesar de esta crítica posible y justa, este estudio puede ser necesario.

Por ejemplo, al estudiar la conciencia jurídica, debemos tener en cuenta que implica componentes invariables y variables. La comprensión de la esencia de los arquetipos es pertinente, ya que ayuda a identificar los citados componentes de la cultura jurídica. Sin embargo, hay que tener en cuenta, qué componentes consideramos. Tenemos que comprender el momento al que pertenecen, en qué nivel de conciencia se sitúan, es decir, si son casuales o es una tendencia generalizada.

\section{¿Por qué de nuevo Cervantes? Los aspectos de la presente investigación}

Don Quijote y Sancho Panza, sin duda, representan arquetipos de la conciencia social y jurídica. Esta cuestión fue propuesta para el estudio por Ana Boitsova (Bojcova, 2008). Partiendo de esta suposición, podemos buscar en la novela de Cervantes ciertos componentes invariables o más o menos variables de la cultura legal española, así como de los acontecimientos históricos.

El objetivo principal de este estudio es el de realizar un ensayo o esbozo para seguir la identificación de los aspectos jurídicos de la época en un texto literario. Para el ejemplo se toma el clásico (y arquetípico) texto de Cervantes. Se propone estudiar dos aspectos que van a marcar las tendencias generales del desarrollo del tema. Se trata de dos aspectos diferentes, pero ambos demuestran cómo es posible, mediante aplicación de la nueva metodología interdisciplinar identificar las facetas de la cultura jurídica que antes quedaban fuera de los límites de estudio de los historiadores del Derecho.

El primer aspecto es el reflejo en un texto literario de las cuestiones de carácter global, incluidas en el objeto de la ciencia de la historia del Estado y del Derecho. Estas son el desarrollo del Estado y del Derecho en general, y de algunas de sus esferas (la relación con la justicia, crimen y castigo, con los funcionarios y el aparato político, con las leyes, etc.). El segundo aspecto, más específico, es la relación del autor (es decir, de un determinado grupo social) con la realidad. En este caso, es interesante entender 
cómo y por qué el escritor elige el género de la parodia y como se implementa, desde el punto de vista de la formación de la imagen artística.

\section{La historia de los galeotes. La doctrina del Derecho natural}

Para contestar la primera cuestión, vamos a estudiar la historia de Don Quijote con los Galeotes. Por un lado, se puede prestar atención a las reflexiones de Don Quijote sobre la equidad y la justicia, y sobre la posibilidad de los estados de quitar la vida y la libertad de los individuos. Por ejemplo el protagonista declara que "podría ser que el poco ánimo que aquel tuvo en el tormento, la falta de dineros deste, el poco favor del otro y, finalmente, el torcido juicio del juez, hubiese sido causa de vuestra perdición y de no haber salido con la justicia que de vuestra parte teníades" (Cervantes, 1605). En estas palabras se puede ver la relación del autor con la Justicia contemporánea y la tarea de los jueces y magisrtado, expresada en nombre de la clase letrada o bien educada en la línea de la ilustración futura. En este mismo sentido se declara otro pensamiento cervantino puesto en boca del protagonista en este mismo capítulo. "Me parece duro caso hacer esclavos a los que Dios y naturaleza hizo libres" (Cervantes, 1605), dice el Caballero de la Triste Figura. Es una declaración directa de las ideas del Derecho natural que en aquella época comienzan a ser muy populares en Europa. Ludovic Asterc (México) investiga las ideas humanas en la novela de Cervantes en su libro, dedicando a este tema un capítulo de su obra y algunas páginas más (Osterc, 1988).

\section{La historia de los galeotes. Un reflejo de los eventos históricos y legales en el pasaje inventado del escritor}

Sin embargo, el más interesante para el presente estudio es otro pasaje. Aquí se menciona el nombre de uno de los galeotes, un tal Ginés de Pasamonte. Liberado entre otros por Don Quijote, primero ataca a su bienhechor y poco después roba el rucio de Sancho. En el Capítulo 27 de la segunda parte nos encontramos de nuevo con Ginés de Pasamonte, es decir, cuando la historia de los galeotes queda en el pasado y el lector ya no recuerda claramente quién era. El Autor nos cuenta entre otras cosas que este criminal "pues, temeroso de no ser hallado de la justicia, que le buscaba para castigarle de sus infinitas bellaquerías y delitos, que fueron tantos y tales, que él mismo compuso un gran volumen contándolos, determinó pasarse al reino de Aragón y cubrirse el ojo izquierdo, acomodándose al oficio de titerero, que esto y el jugar de manos lo sabía hacer por estremo" (Cervantes, 1605). Esto sí pudo ser posible porque 
en Aragón no funcionó plenamente el Derecho de Castilla a causa de la presencia en el sistema de Derecho de los fueros privilegiados otorgados por el reino de Castilla en el proceso de la integración.

Sin embargo, vamos a destacar el hecho de que estamos en el principio del siglo XVII. Esto quiere decir que el proceso de la formación del territorio unido del Estado acabó cien años antes más o menos. Ya son pasado el primer Emperador auténtico Carlos I de España y V de Alemania y el tirano Felipe II. España es un imperio mundial reconocido, que extiende su dominio a los países europeos y los de ultramar. A pesar de todo, un criminal dentro del Estado solo necesita atravesar la frontera para esquivar el castigo no de Castilla, sino de España. El caso parece muy interesante y digno de estudio. El estudio nos permitirá revelar unos aspectos de la realidad legal de España en el principio del siglo XVII y también la manera de la que se refleja esta realidad en la conciencia de la clase educada. Obviamente, esta realidad reflejada en el texto de ficción difiere de la realidad reflejada en el texto legal. El texto legal para un historiador de Derecho es la fuente auténtica, y según esta fuente la realidad de España es otra, porque el Estado ya es un hecho jurídico, indudable. De esta manera tenemos dos realidades o dos imágenes del mundo diferentes. Una realidad es la del lector de la novela (y tal vez del escritor) y otra realidad es la del historiador del Derecho. En una realidad tenemos el Estado descompuesto, en proceso de formación. En otra realidad tenemos el Estado ya integrado desde hace cien años.

Para resolver esta contradicción necesitamos aceptar una hipótesis de trabajo que consiste en que en la novela podemos observar la alusión del autor a la situación real, o, tal vez, a unos casos reales que confirmarían esta situación. Esto puede ser verdad, porque la conciencia de un individuo no refleja la realidad como tal, sino ciertos acontecimientos que dejan huella en su conciencia. Después hay que comparar casos fijados en las fuentes tradicionales y los de la novela. Es necesario para comprobarlos. Hay que comprender que el autor no es capaz de inventar algo que no tiene raíces en la realidad. La fantasía es un mecanismo psicológico de reproducción de la información de forma diferente de la original y que posee la misma esencia.

En nuestro caso en la novela cervantina se habla de forma velada de los acontecimientos actuales, es decir, el asíl llamado “caso de Antonio Pérez", el secretario de Felipe II. Este hombre después escribió muchas páginas de la llamada Leyenda Negra sobre su antiguo Señor y sobre toda España. De esto en particular habla Bruno Aguilera Barchet (Aguilera Barchet, 2006). Para nosotros es importante que este señor (Antonio Pérez) se consideraba uno de los estafadores y aventureros más famosos de 
su época. En el año 1590 fue detenido en Madrid, pero pudo evadirse de la Justicia y escapar de la persecución a la ciudad de Zaragoza, es decir, en el Reino de Aragón. Esto pudo ser verdad gracias a un fuero que permitió al gobierno de Aragón no entregar a los malhechores si se reconocían aragoneses. La familia de Pérez procedía de Aragón y, aunque el mismo Antonio ya no tenía ninguna relación con el Reino e incluso no visitaba esta tierra, se reconoció aragonés. De ahí huyó a Francia, donde murió en el año 1611.

Este pasaje de la novela nos permite reconstruir la realidad legal de la época, subrayar y analizar los casos legales y estudiar la relación de los contemporáneos con estos casos. Por último, se hace relevante este tipo de análisis porque un lector puede preguntar, ¿por qué el investigador asenderea en lugar de seguir el camino trillado? Es importante el aspecto de la relación del escritor con la realidad actual. Vamos a estudiar cómo se forma la imagen del protagonista en base a la conciencia jurídica del autor.

\section{La restauración de la conciencia jurídica del autor (o de la clase culta) de la época}

Bastante importante es estudiar el segundo aspecto en el ejemplo de los capítulos 42 y 43, en los cuales Don Quijote da consejos a Sancho, el futuro gobernador de la Isla. En estos dos capítulos se ve el nivel muy alto de educación y el conocimiento profundo de la realidad legal y de los textos medievales del mismo Cervantes, que también mencionó en el artículo citado O. Aurov. El historiador dijo que Cervantes sin duda conocía muy bien la legislación como mínimo desde el siglo XIII, y esto es evidente, porque en la novela se reproducen las normas que determinaban el estatuto de la caballería (Aurov, 2014). Pero también se observa muy claramente el conocimiento profundo de tratados jurídicos divulgados en la época medieval y moderna. Eran tratados romanos y de los legistas de España.

También hay que subrayar que está claro que un gran número de lectores tenía que conocer profundamente estos tratados, porque en otro caso el sentido de la ironía del escritor se hubiera perdido. Es conocido que en la novela se encuentran no solo alusiones a estos tratados, sino parodias políticas y sociales. Antes solo habían mencionado la parodia sobre las novelas de caballería. También es conocido que el público tomó la novela por humorística y por eso provocó muchas risas. Vladímir Nabókov en una de sus lecciones dedicadas a Don Quijote citó una leyenda relacionada con la novela (Nabokov, 2002: 85). Cuenta la leyenda que un día Felipe III al despertarse miró desde 
la ventana y se asombró al ver a un joven sentado bajo el árbol que "rompió a carcajadas impetuosamente". El Rey hizo la observación de que evidentemente el joven o bien estaba loco o leía Don Quijote. Como pueden adivinar, la última mención fue cierta. Al márgen se puede marcar la incomprensión sincera de V. Nabókov de la posibilidad de poder reírse de las situaciones descritas en la novela cervantina. Es un hecho muy curioso, de carácter psicológico, que es una cuestión para otra investigación, porque un lector moderno tampoco comprende el humor de la obra de arte de Cervantes. Para nosotros este hecho no es el objetivo del presente artículo, porque no importa si un lector moderno se ríe o no al leer la novela. Para esta investigación es importante subrayar que un lector del siglo XVII consideraba esta novela divertida. Los lectores del siglo XVII comprendían con qué o con quién se comparaban los personajes o los acontecimientos y en esta comparación veían algo divertido que les hacía reír a carcajadas. Podemos suponer que tanto el autor como los expectadores compartían las mismas referencias. Desde el punto de vista de la psicología moderna, una risa se produce, por ejemplo, por hacer una comparación inesperada, y ambas cosas (lo comparado y con qué se compara la cosa) tienen que ser conocidas por el lector.

Expresamos una hipótesis basada en la investigación de las fuentes: que el Capítulo 42 puede ser una parodia a un típico tratado jurídico y el Capítulo 43 es una parodia de otro género muy popular en la España Medieval, el de los Espejos o Especulos. Estos son las colecciones metodológicas de los concejos dirigidos a los príncipes o incluso a los Reyes de parte de los sabios. Podían ser consejos de cómo vestirse, de la forma de comportarse, del Gobierno y, en general, de la educación del monarca ideal. Comparamos los dos consejos de los "Espejos" y de la novela. El primer consejo es dado por el cardenal Roberto Bellarmino, Santo, en el mismo tiempo que escribió Cervantes.

Quanto a lo primero hase de considerar atentamente, quales sean las virtudes que se requieren, para que el Principe bien y derechamente haga su oficio y aunque para gouernar bien los Reynos sea menester muchas vircudes, asi conforme a las Sagradas Letras, como a las leyes de los Filosofos, un empero es la principal, que todas las otras trae consigo,que es la caridad paternal a quien como ministras y companeras siguen las virtudes Cardinal es, Prudencia, Justicia, Forraleza, y Templança, que son comunes al Principe y a los vaslallos, auiédo otras que son propias de los Principes, como la Sabiduria, Magnificencia, Clemencia, y Misericordia, las quales la Escritura Sagrada suele alabar en Dios Rey de los Reyes (Bellarmino, 1640: I, 7). 
El segundo consejo es dado por Cervantes en su novela.

- En lo que toca a cómo has de gobernar tu persona y casa, Sancho, lo primero que te encargo es que seas limpio y que te cortes las uñas, sin dejarlas crecer, como algunos hacen, a quien su ignorancia les ha dado a entender que las uñas largas les hermosean las manos, como si aquel escremento y añadidura que se dejan de cortar fuese uña, siendo antes garras de cernícalo lagartijero, puerco y extraordinario abuso.

No andes, Sancho, desceñido y flojo, que el vestido descompuestoI da indicios de ánimo desmazalado, si ya la descompostura y flojedad no cae debajo de socarronería, como se juzgó en la de Julio César (Cervantes, 1605).

Por la comparación de la forma, del contenido y del estilo se puede llegar a la conclusión de que estas dos partes son, por lo menos, parecidas y de que, además, los autores utilizan los mismos métodos para conseguir el mismo resultado.

\section{La parodia como una forma de expresar la conciencia jurídica de la época. ¿Por qué este genero y qué puede constatar?}

Hasta ahora hemos hecho un esbozo sobre lo que parodió Cervantes. Lo último que queda por mencionar en este breve ensayo es por qué la conducta legal del personaje se manifiesta por medio de la parodia. Cervantes mediante las acciones y el pensamiento del protagonista parodió los principios legales de su época que eran el fundamento para la formación de la conciencia jurídica de los individuos.

Para contestar esta pregunta es necesario ante todo y, sobre todo, tener en cuenta el esquema de los pilares de la sociedad, desde el punto de vista del Derecho. Primero, está el espacio de la cultura legal oficial (el mundo de la norma). En segundo lugar, está la cultura marginal (el mundo de la antinorma). Entre estas dos zonas se extiende un espacio fronterizo, muy amplio, de la cultura legal consuetudinaria. En este espacio se encuentra la mayoría de la gente. Este espacio fronterizo se compone de su simultánea pertenencia a los dos mundos. Este espacio los separa y une a la vez, formando un fenómeno cultural independiente.

Este tipo de reconstrucción del modelo de la sociedad permite explicar la presencia del mito sobre un bandolero caballero. Este es un típico fenómeno fronterizo. Esta figura es igualmente inaceptable en los dos mundos, en el de la cultura y en el de la anticultura. Sin embargo, pertenece a los dos. También una figura típica fronteriza es la de Sancho Panza. Un patrón de este tipo de la conciencia legal es la Justicia, no el Derecho. "Sancho Panza is a character representing everyone's mentality in the 
eternal and infinite aspiration for justice" (Kalinina, 2014: 344). Es la conciencia legal ordinaria, bien conocida por Cervantes.

Don Quijote, gracias a su procedencia, es un fenómeno de la cultura oficial. Si alguna vez desea salir de este espacio social, no puede encontrarse automáticamente en el mundo de la antinorma (a no ser que cometiese un crimen) ni siquiera en el espacio fronterizo (el conflicto entre nobleza y villanaje es mental). Es una particularidad muy importante de esta parte pequeña de la sociedad que se forma en la zona de la cultura oficial. Sin embargo, de vez en cuando salir de este espacio es vitalmente importante.

"Vamos a imaginar que algún grupo cultural supone que una cierta esfera de su actividad es rígidamente controlada, que esta esfera no le representa como personalidad, sino como un material de relleno de los esquemas funcionales reglamentados... Cuando está presente este tipo de conciencia, este grupo cultural de la masa general (de su conducta social) aparta otra esfera, en este caso de la conducta interna (es decir, dentro del grupo), y las normas de esta conducta van a ser vueltas al revés en comparación con las normas primarias, o parodiadas. Es fácil notar que el descrito mecanismo sobre el fondo es análogo al mecanismo de la carnavalización descrita de M. Bajtín" (Zhivov, 1996: 213).

\section{Conclusión. Problemas esbozados para la futura investigación}

Don Quijote parte para encontrar la justicia, pero no le encaja la justicia de Sancho Panza (y la de toda su clase), la justicia de la cultura legal consuetudinaria. No le parece adecuada. Parece que busca otra justicia, más justa. Esta justicia tendría que distinguirse de las normas oficialmente declaradas, pero debería ser diferente a las normas de la gente ordinaria y de los villanos. Por esto lo primero que hace Don Quijote es negar los principios de la cultura y del Derecho bien conocidos. Por eso pone del revés las normas propias de su clase y de su educación. Cervantes subraya este hecho incluso en un nivel físico, como podemos observar en el pasaje en que el protagonista da vueltas, desnudando su cuerpo al ponerse sobre la cabeza. De esta misma manera las normas sociales puestas al revés se convierten en parodia, lo que pasaba a menudo en la Edad Media durante los carnavales. En esta situación Don Quijote no tiene otra salida que la de ser un bufón, creando su propia antinorma, porque no puede cometer un crimen (para ser una parte del mundo de la anticultura).

En esta breve investigación se ha presentado un posible guía de trabajo de los problemas que hay que resolver y se proponen algunas propuestas de resolución. La idea fundamental ha sido demostrar la posibilidad y la necesidad de aplicar en la 
historia del Derecho y del Estado fuentes poco tradicionales para estudiar la conciencia legal consuetudinaria de la época.

\section{Bibliografía}

Aguilera Barchet, B. (2006). The Law in the Story about Quijote: Notes for the Legal Inmersion in Spain of the Golden Age [El Derecho en el Quijote: notas para una inmersión jurídica en la España del Siglo de Oro]. In Anuario de historia del Derecho español, 76, 173-214.

Aurov, O.V. (2014). "Ispolnjaja dolg vsego rycarstva": zametki istorika-medievista na poljah romana Servantesa [Como está a cargo de la caballería: Some Glosses of a Medievalist on the Novel by Miguel de Cervantes]. In Novyj filologicheskij vestnik [The New Philological Bulletin], 2 (29), 116-128.

Bellarmino, R. (1640). Officio del principe christiano del cardenal Roberto Belarmino y auisos vtiles para el gouierno politico militar y domestico. Madrid, 340 p.

Bojcova, A.P. (2008). Arhetipy ispanskoj kul'tury [Archetypes of the Spanish Culture]. In Znanie. Ponimanie. Umenie [Knowledge. Understanding. Skill], 1, 239-243.

Cervantes, Miguel de (1605). Don Quijote de la Mancha. Madrid, Edición del Instituto Cervantes, available at: http://cvc.cervantes.es/literatura/clasicos/quijote

Kalinina, E. (2014). Don Quixote and Sancho Panza as the Symbols of the Truth and Justice. In Journal of Language and Literature, 5, 4, 343-346.

Nabokov, V.V. (2002). Lekcii o Don Kihote [Lectures about Don Quixote]. Moscow, Nezavisimaja gazeta, $328 \mathrm{p}$.

Osterc, L. (1988). The Social and Political Thought in the Story about Quixote: the Historical-Materialistic Interpretation [El pensamiento social y politico del Quijote: interpretación histórico-materialista]. Mexico, UNAM, 370 p.

Ponomarev, V.V. (2016). Paroksizmal'noe sostojanie v romane 'Hitroumnyj idal'go Don Kihot Lamanchskij" [Paroxysmal condition in the novel "Ingenious hidalgo Don Quixote"]. In Mezhdunarodnyj nevrologicheskij zhurnal; MNZh. [International neurologic journal], 1 (79), 169-171.

Sabitova, Z.K., \& Ekshembeeva, L.V. (2012). Konflikt mirov v mnogomernom prostranstve romana M. Servantesa «Don Kihot» [The conflict of worlds in the the multidimentional novel of M.Cervantes "Don Quixote"]. In Jazyk. Tekst. Diskurs [Language. Text. Discourse], 10, 197-202.

Zhivov, V. (1996). Koshhunstvennaja pojezija v sisteme russkoj kul'tury konca XVIII - nachala XIX v. [Blasphemous Poetry in the system of Russian culture at 
the close of the $18^{\text {th }}$ century and the beginning of $19^{\text {th }}$ century]. In Anti-mir russkoj kul'tury. Jazyk, fol'klor, literature [Anti-world of the Russian culture. Language, folklore, literature], 189-231.

\section{Дон Кихот и Санчо Панса как архетипы испанского правосознания. Новая методология в истории государства и права}

Е.Ю. Калинина

Российский государственньий педагогический университет им. А.И. Гериена Россия, 191186, Санкт-Петербург, наб. р. Мойки, 48

Особый интерес в данном исследовании представляют два аспекта. С одной стороны, предлагается новая методология исследования, построенная на фундаменте междисциплинарного научного подхода. С другой стороны, рассматриваются результатьл применения новой методологии на примере разбора романа «Дон Кихот».

В рамках истории государства и права предлагается использовать методы, свойственные другим гуманитарным наукам, в чей предмет изучения входят подобные феномень. Например, государство в той или иной мере изучается разными науками, а, следовательно, более полная картина, несомненно, сложится, если мы сложим мозаику из разных элементов.

Такой подход предполагает использование нетрадииионных источников, которые ранее в юриспруденции находились под неформальным запретом. В качестве такого источника используется художественный текст. В процессе исследования показано, что через художественный текст можно реконструировать ряд историко-правовых событий. С другой стороны, что более важно, посредством анализа текста можно выявить особенности правосознания изучаемой эпохи.

Ключевые слова: правосознание, междисииллинарньй подход, архетипь, история государства и права, Сервантес, Дон Кихот, Испания XVII в.

Научная специиальность: 10.00.00 - филологические науки. 